\title{
Determination of Total Flavonoids and Its Antioxidant Ability in Houttuynia cordata
}

\author{
Anyin Chen ${ }^{12 *}$, Wenjun Xiang1,2, Dan Liu1, Changlu Liu', Li Yang1 \\ ${ }^{1}$ Key Laboratory of Exploitation and Study of Distinctive Plants in Education Department of Sichuan Province, \\ Sichuan University of Arts and Science, Dazhou, China \\ ${ }^{2}$ Department of Chemistry and Chemical Engineering, Sichuan University of Arts and Science, Dazhou, China \\ Email: "anyinchen@163.com
}

Received 8 December 2015; accepted 25 February 2016; published 29 February 2016

Copyright (C) 2016 by authors and Scientific Research Publishing Inc.

This work is licensed under the Creative Commons Attribution International License (CC BY). http://creativecommons.org/licenses/by/4.0/

(c) (i) Open Access

\section{Abstract}

The total flavonoids of Houttuynia cordata are determined by UV-Vis spectrophotometry. The extraction condition of flavonoids from Houttuynia cordata includes: the extraction temperature is $70^{\circ} \mathrm{C}$, solid-liquid ratio is $1: 20$, solvent is $80 \%$ ethanol, extraction time is $65 \mathrm{~min}$. We studied the antioxidation of flavonoids in Houttuynia cordata, and results showed that flavonoids had strong reducing capacity, hydroxyl free radical scavenging activity and the superoxide anion radical scavenging ability, thus can provide a basis for the development of natural antioxidants.

\section{Keywords}

\section{Houttuynia cordata, Total Flavonoids, Antioxidant Capacity}

\section{Introduction}

As a common plant, Houttuynia cordata is widely distributed in the area of southeast, central region and southwest of China. It is not only used as great food material, but also a medicine for curing various diseases. Containing flavonoids anti-cancer agent, the Houttuynia cordata has preferable effects on the treatment of gastric cancer and certain therapeutical effects on lung cancer and colorectal cancer of the middle and advanced stage [1]. Apart from that, it also has a function with healthcare, such as commonly used in the healthcare food like tea drinks.

Since flavonoids could not be synthesized in the body, it is merely brought from plants. Therefore, to better extract and separate flavonoids from the Houttuynia cordata, the determination of the total amount of flavonoids and in vitro antioxidant capacity are carried out, providing references for the reasonable utility of the resource,

\footnotetext{
${ }^{*}$ Corresponding author.
}

How to cite this paper: Chen, A.Y., Xiang, W.J., Liu, D., Liu, C.L. and Yang, L. (2016) Determination of Total Flavonoids and Its Antioxidant Ability in Houttuynia cordata. Journal of Materials Science and Chemical Engineering, 4, 131-136. 
as well as the theoretical basis and technical support for quality control and pharmacological activity research.

\section{Experimental Part}

\subsection{Materials and Instruments}

Ultraviolet and visible spectrophotometer (UV-2550), centrifugal machine (TG20-WS), electronic scales (FA1104N), draught drying cabinet (101-2AB), herbal medicine grinding machines (FW-135), sieve (60 mesh). Houttuynia cordata (bought from Dazhou, Sichuan) was proceeded with wash, natural withering, drying to constant weight, and then smash for use. The reagents include rutin standard sample, ethyl alcohol, ethyl alcohol, aluminium nitrate, sodium nitrite, distilled water, petroleum ether, trichloroacetic acid and vitamin C.

\subsection{Experiment Method}

\subsubsection{Standard Curve of Rutin}

Twenty milligram of rutin standard sample is precisely weighed and dissolved in the solution with $40 \%$ ethyl alcohol. Then, the solution was transferred to the volumetric flask of $100 \mathrm{~mL}$ prior to metered volume and shaking up. In this way, a solution with mass concentration of $0.2 \mathrm{mg}$ rutin per milliliter is obtained. A series amount of the standard solution, including $0,1.0 \mathrm{ml}, 2.0 \mathrm{ml}, 1.0 \mathrm{ml}, 6.0 \mathrm{ml}, 8.0 \mathrm{ml}$ and $10.0 \mathrm{ml}$, are added into seven 25 $\mathrm{ml}$ volumetric flasks, respectively. Then $12.5 \mathrm{~mL} 40 \%$ ethanol solution, $0.5 \mathrm{~mL} \mathrm{NaNO}_{2}$ (1:20) solution with mass fraction of $5 \%$, are added in each of the volumetric flasks, and left for $5 \mathrm{~min}$. The $\mathrm{Al}\left(\mathrm{NO}_{3}\right)_{3}$ solution with the mass fraction of $10 \%$ was injected prior to shaking up. After left for $5 \mathrm{~min}, 4 \mathrm{~mL}$ sodium hydroxide solution (1:25) was added, and the solution was homogeneously mixed. Finally, $40 \% \mathrm{CH}_{3} \mathrm{CH}_{2} \mathrm{OH}$ was added to calibrate the mixture, and then left for $10 \mathrm{~min}$. With distilled water as blank control, the absorbance of the solution was measured at $510 \mathrm{~nm}$ by ultraviolet spectrophotometer. The Rutin standard curve was drawn with the rutin concentration as abscissa and absorbance the ordinate [2].

\subsubsection{The Extraction Condition of Flavonoids}

The grass of Houttuynia cordata was dried, smashed and sieved to 60 mesh, prior to immersing into petroleum ether for $2 \mathrm{~h}$ (Figure 1). After the supernatant was discarded, petroleum ether was added to immerse the grass again, until the colorless supernatant was observed. Then the sample was dried with drying cabinet $\left(70^{\circ} \mathrm{C}\right)$. Four grams of the Houttuynia cordata powder was taken into return pipe of the Soxhlet extractor along with $120 \mathrm{ml} 80 \%$

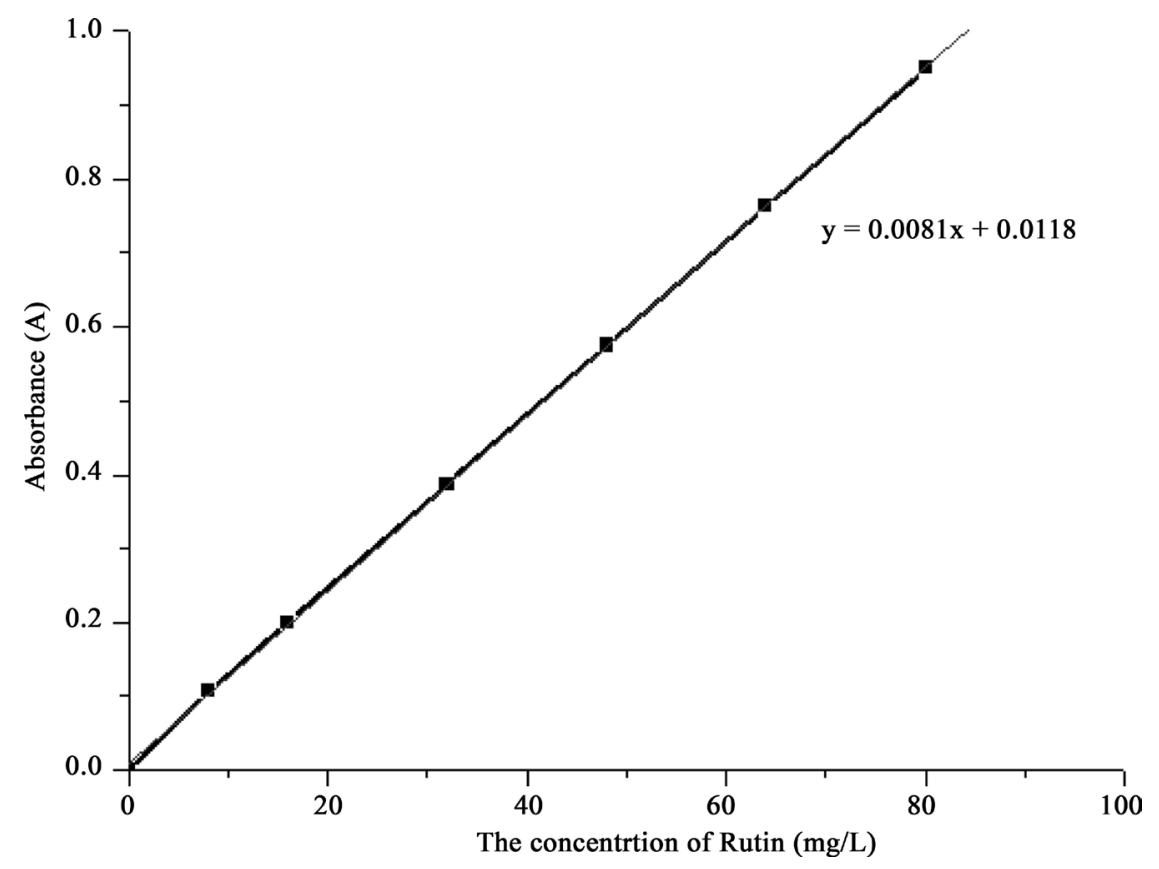

Figure 1. Standard curve of rutin. 
ethanol solvent. Reflux extraction was carried out at $70^{\circ} \mathrm{C}$ for 65 min [3]. Flavonoids filtrate was obtained by vacuum filtration from the extract. After five milliliter of flavonoids filtrate was fetched from the volumetric flask, a solution containing 5 percent of $\mathrm{NaNO}_{2}$ was added into the mixture before homogenously mixed and left for $5 \mathrm{~min}$. Similarly, the solution of 10 percent $\mathrm{Al}\left(\mathrm{NO}_{3}\right)_{3}$ was added, mixed and left for $1.5 \mathrm{~min}$, before 4 $\mathrm{mL} 1 \mathrm{~mol} / \mathrm{L}$ sodium hydroxide was mixed. In the end, $40 \%$ ethyl alcohol was used to calibrate, then it was left for $10 \mathrm{~min}$. The flavonoids content was calculated by the method of determining absorbance using ultraviolet spectrophotometer.

\subsubsection{The Calculation of Flavonoids Content}

According to the experimental process, the amount of extract could be indicated as follows:

The content of flavonoids: $H=\frac{C V}{M}$.

$C$ is the concentration of the extract, $\mathrm{mg} / \mathrm{mL} ; V$ is the volume of the extract, $\mathrm{mL} ; M$ is the mass of the sample, g.

The absorbance of the Houttuynia cordata sample was tested to be 0.574 , and the responding concentration was $0.048 \mathrm{mg} / \mathrm{mL}$ according to the standard curve. Therefore, the content of the flavonoids was $12 \mathrm{mg} / \mathrm{g}$.

\subsubsection{Research on the Reducing Power of Flavonoids}

The filtrate was concentrated into a flavonoids-ethanol solution with mass concentration of $500 \mathrm{mg} / \mathrm{L}$, in order to examine the antioxidant activity.

By using the prepared solution, a series of flavonoids sample solution were obtained, of which the concentration were $10 \mathrm{mg} / \mathrm{L}, 20 \mathrm{mg} / \mathrm{L}, 30 \mathrm{mg} / \mathrm{L}, 40 \mathrm{mg} / \mathrm{L}$ and $50 \mathrm{mg} / \mathrm{L}$, respectively. Taking $1.0 \mathrm{ml}$ different mass concentration of flavonoids sample solution, $3.0 \mathrm{~mL} \mathrm{H}_{3} \mathrm{PO}_{4}(\mathrm{pH}=6.6,0.2 \mathrm{~mol} / \mathrm{L})$ and $2.5 \mathrm{ml}$ solution which contains $1 \%$ mass fraction of $\mathrm{Fe}(\mathrm{SCN})_{3}$ into a $10 \mathrm{ml}$ centrifuge tube, the mixture was homogenously mixed and maintained at $60^{\circ} \mathrm{C}$ for $25 \mathrm{~min}$. Afterwards, the mixture was subject to cold water and amended with $2.5 \mathrm{~mL}$ $10 \%$ trichloroacetic acid, and the distilled water was used for calibration. After the centrifugation in a speed of $2500 \mathrm{r} / \mathrm{min}, 2.5 \mathrm{~mL}$ supernatant was taken to mix $0.1 \% 1.0 \mathrm{~mL} \mathrm{FeCl}_{3}$ and distilled water. 15 min later, its absorbance was determined at $700 \mathrm{~nm}$ using ultraviolet spectrophotometer. Distilled water and vitamin C were used as reference and control, respectively.

\subsubsection{Research on the Hydroxyl Free Radical Scavenging Ability of Flavonoids}

By using certain amount of the standby solution, $10 \mathrm{ml}$ flavonoids sample solution were prepared under different concentration ( $50 \mathrm{mg} / \mathrm{L}, 100 \mathrm{mg} / \mathrm{L}, 150 \mathrm{mg} / \mathrm{L}, 200 \mathrm{mg} / \mathrm{L}, 250 \mathrm{mg} / \mathrm{L})$. For flavonoids samples of different mass concentration, $1.0 \mathrm{ml}$ of the solution prepared above was injected into the five test tubes, respectively. Then 1.0 $\mathrm{ml} / \mathrm{L} 10 \mathrm{mmol} / \mathrm{L} \mathrm{FeSO}_{4}$ and $1.0 \mathrm{ml} 10 \mathrm{mmol} / \mathrm{L}$ salicylic acid-ethanol solution were added into the tube, which was consequently placed in a water bath at $37^{\circ} \mathrm{C}$ for $35 \mathrm{~min}$ prior to taking out and calibration to the scale line with distilled water. Using ultraviolet spectrophotometer, the absorbance was measured at $510 \mathrm{~nm}$ with distilled water as a reference and vitamin $\mathrm{C}$ as control. The hydroxyl radical scavenging rate was calculated as follows [4].

$$
Y=\frac{A_{0}-\left(A_{x}-A_{x 0}\right)}{A_{0}} \times 100 \%
$$

In the equation, $Y$ represents the scavenging rate, $A_{0}$ denotes the absorbance of control, $A_{x}$ is the absorbance of the sample after the flavonoid solution was added, and $A_{x 0}$ is the absorbance of flavonoids solution with no $\mathrm{H}_{2} \mathrm{O}_{2}$.

\subsubsection{Research on the Superoxide Anion Radical Scavenging Ability of Flavonoids}

By using certain amount of the standby solution, $10 \mathrm{ml}$ flavonoids sample solution were prepared under different concentration ( $50 \mathrm{mg} / \mathrm{L}, 100 \mathrm{mg} / \mathrm{L}, 150 \mathrm{mg} / \mathrm{L}, 200 \mathrm{mg} / \mathrm{L}, 250 \mathrm{mg} / \mathrm{L}$ ). For flavonoids samples of different mass concentration, $1.0 \mathrm{ml}$ of the solution prepared above was injected into the five test tubes, respectively. Then 4.0 $\mathrm{ml} / \mathrm{L}$ Tris (hydroxymethyl) metyl aminomethane- $\mathrm{HCl}$ buffer solution $(\mathrm{pH}=8.2,50 \mathrm{mmol} / \mathrm{L})$ were added into the tube, which was consequently placed in a water bath at $25^{\circ} \mathrm{C}$ for $25 \mathrm{~min}$ prior to the addition of $0.1 \mathrm{~mL} 25$ 
$\mathrm{mmol} / \mathrm{L}$ pyrogallic acid. After the mixing, the water bath was carried out again at $25^{\circ} \mathrm{C}$ for 6 min. Then two droplets of $10 \mathrm{~mol} / \mathrm{L} \mathrm{HCl}$ solution were injected to terminate the reaction. Using ultraviolet spectrophotometer, the absorbance was measured at $325 \mathrm{~nm}$ with Tris (hydroxymethyl) metyl aminomethane-HCl buffer solution as a reference and vitamin $\mathrm{C}$ as control. The hydroxyl radical scavenging rate was calculated as follows [4].

$$
Y=\frac{A_{0}-\left(A_{x}-A_{x 0}\right)}{A_{0}} \times 100 \%
$$

In the equation, $Y$ represents the scavenging rate, $A_{0}$ denotes the absorbance of control, $A_{x}$ is the absorbance of the sample after the flavonoid solution was added, and $A_{x 0}$ is the absorbance of flavonoids solution with no pyrogallic acid.

\section{Results and Discussion}

\subsection{The Reducing Power of Flavonoids}

The reduction ability mainly refers to determining whether the substance could provide electron for reducing oxidant. The extent of reduction ability was examined by comparing the absorbance value. The greater value of absorbance represents the stronger reduction ability. The reduction ability of substance has a close association with its antioxidant capacity, and a stronger material reducing ability indicates stronger oxidation resistance.

Figure 2 shows that in the tested concentration range, with the increase in the concentration of flavonoids in Houttuynia cordata. Furthermore, the reduction ability promoted by the flavonoids, appeared to be equivalent to vitamin $\mathrm{C}$ with the same mass concentration, indicating a preferable reduction ability of the flavonoids.

\subsection{Elimination Ratio of Hydroxyl Radicals of Flavonoids}

Hydroxyl free radicals, which is a kind of active oxygen radicals, is apt to attack other molecules, such as biological molecules, organic matter or inorganic matter. Hydroxyl free radicals work through a variety of interactions, including electron transfer, additive reaction and dehydrogenation, resulting in the oxidation of DNA, amino acids, protein, carbohydrate substances. Consequently, the cell necrosis or mutations emerges in the living organism.

In this experiment, the hydroxyl radicals can react with salicylic acid and generate colored product which has strong absorption at the wavelength of $530 \mathrm{~nm}$. The addition of a substance that possesses hydroxyl radical scavenging ability to compete with salicylic acid will lower the yield of the colored product resulting from hydroxyl radical oxidation.

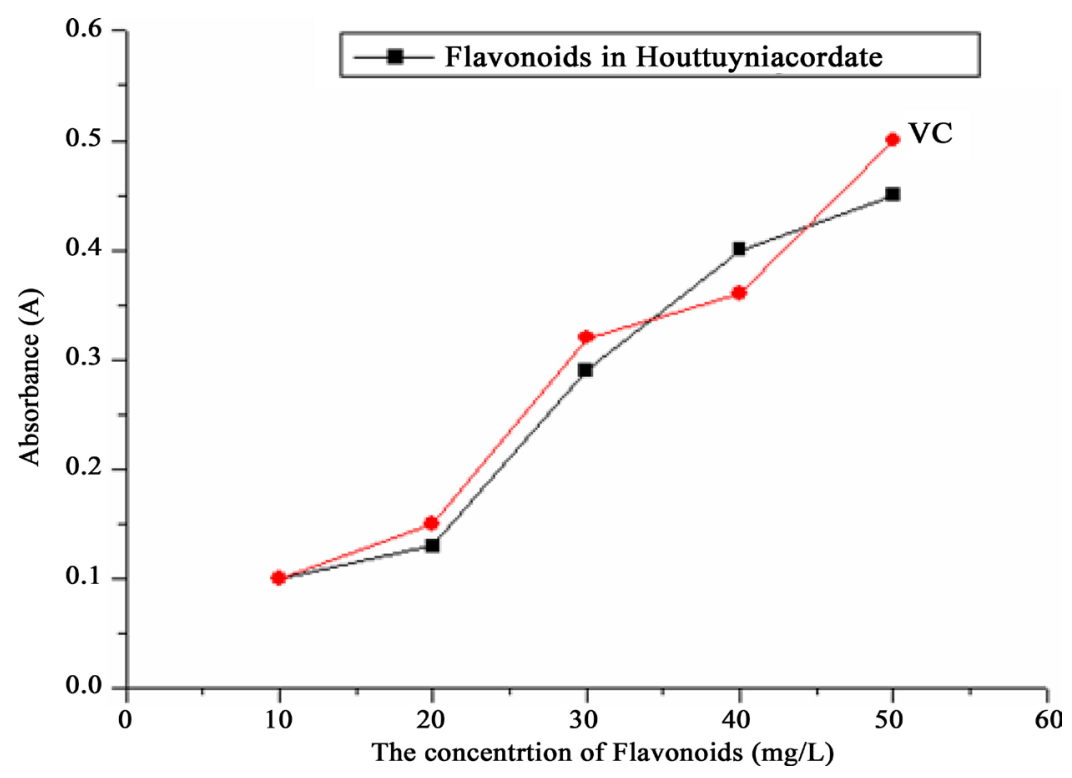

Figure 2. The reducing power of flavonoids in Houttuynia cordata. 
As is seen from Figure 3, in the tested mass concentration range, hydroxyl free radical scavenging effect of the flavonoids is enhanced by the increase in the concentration of flavonoids. As a result, flavonoids have stronger hydroxyl radical scavenging ability than vitamin C.

\subsection{Elimination Ratio of Superoxide Anion Radical of Flavonoids}

The excessive superoxide anion free radical, due to its relative high activity, can cause damage to tissue of human body. The product resulted from the combination of superoxide anion free radical with hydroxyl radical in vivo, will finally lead to DNA damage in cell and normal function in human body. Under the alkaline condition, the oxidation will occur to the pyrogallic acid itself, and produces colored intermediate and superoxide anion, of which higher concentration result in faster oxidation rate of catalytic reaction. However, quick reaction of antioxidants with superoxide anion can inhibit the oxidation of pyrogallic acid.

Figure 4 shows that in the tested concentration range, the flavonoids have the ability to remove superoxide

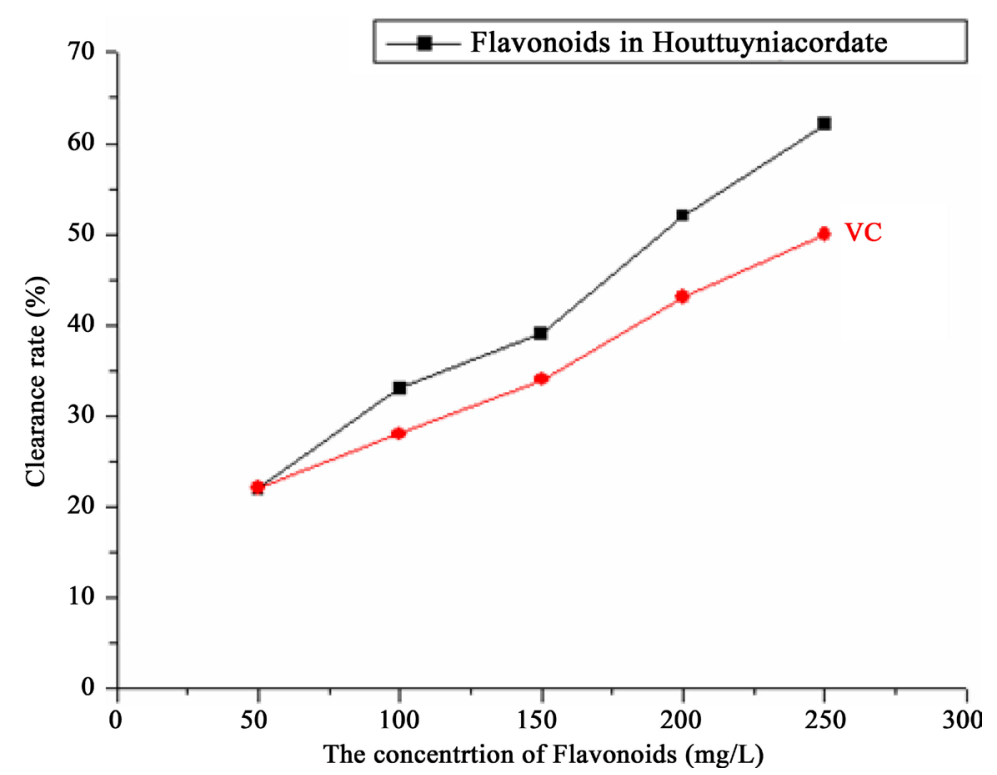

Figure 3. Elimination ratio of hydroxyl radicals of flavonoids.

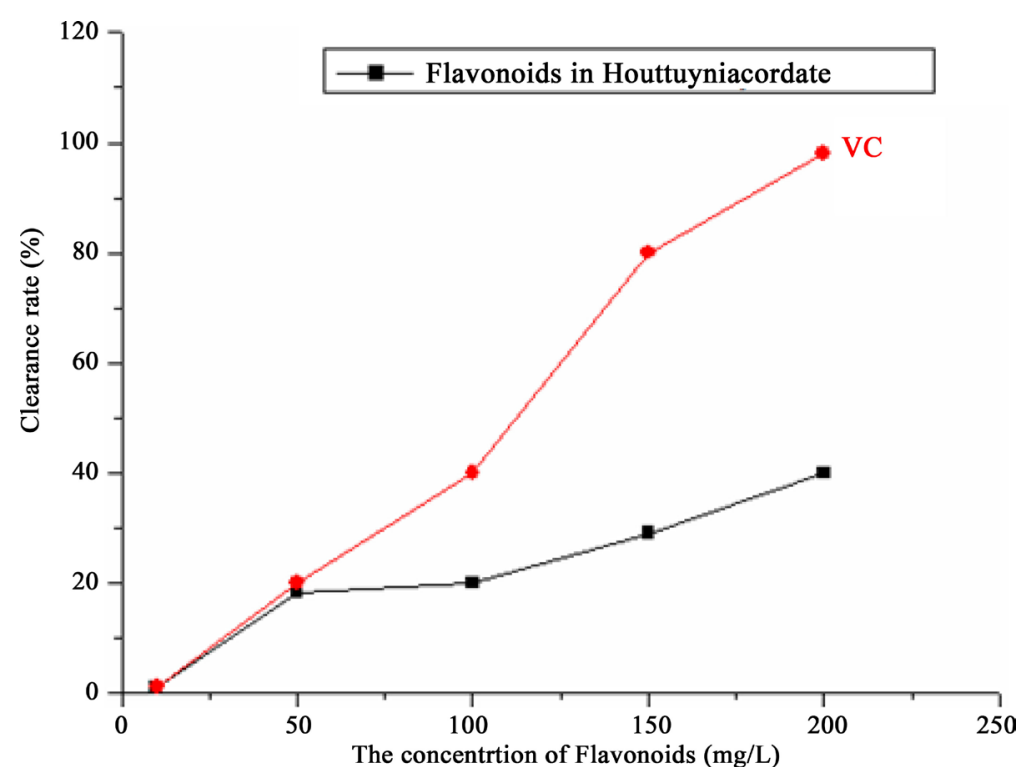

Figure 4. Elimination ratio of superoxide anion radical of flavonoids. 
anion free radicals. Higher mass concentration of Houttuynia cordata flavonoids give rise to the greater scavenging effect of superoxide anion free radical, which is equivalent to that of the vitamin $\mathrm{C}$, in the range of mass concentration from 0 to $50 \mathrm{mg} / \mathrm{L}$. When the mass concentration is greater than $50 \mathrm{mg} / \mathrm{L}$, scavenging effect of superoxide anion free radical appeared to be relative low, compared to vitamin $\mathrm{C}$, and the difference increases with the increase of the mass concentration.

In northeast area of Sichuan, total content of flavonoids in the whole grass of Houttuynia cordata powder sample is $12 \mathrm{mg} / \mathrm{g}$.

\section{Conclusions}

The result of antioxidant test in vitro indicates that flavonoids in Houttuynia cordata have strong reducing ability, and their ability of reducing is comparable to vitamin $\mathrm{C}$ with similar mass concentration. Compared with the vitamin $\mathrm{C}$ in the same mass concentration, flavonoids in Houttuynia cordata possess weak superoxide anion radical scavenging ability; in contrast, the hydroxyl radical scavenging ability of flavonoids is stronger.

In summary, flavonoid is not only a kind of good natural antioxidant, but also a natural health product. Therefore, it will be widely used as a functional food and medicine in the future. Since many problems exist in the synthesized antioxidants, such as insecurity and deleteriousness, the natural antioxidant will gain a larger market advantage and will be better accepted by us.

\section{Acknowledgements}

This study was financially supported by the scientific research fund of Key Laboratory of Exploitation and Study of Distinctive Plants in Education Department of Sichuan Province (sctz201306).

\section{References}

[1] Abdolghaffari, A.H., Baghaei, A., Moayer, F., Esmaily, H., Baeeri, M., Monsef-Esfahani, H.R., et al. (2010) On the Benefit of Teucrium in Murine Colitis through Improvement of Toxic Inflammatory Mediators. Human \& Experimental Toxicology, 29, 287-295. http://dx.doi.org/10.1177/0960327110361754

[2] Sharififar, F., Dehghn-Nudeh, G. and Mirtajaldini, M. (2009) Major Flavonoids with Antioxidant Activity from Teucrium polium L. Food Chemistry, 112, 885-888. http://dx.doi.org/10.1016/j.foodchem.2008.06.064

[3] Hinneburg, I., Dorman, H.J.D. and Hiltunen, R. (2006) Antioxidant Activities of Extracts from Selected Culinary Herbs and Spices. Food Chemistry, 97, 122-129. http://dx.doi.org/10.1016/j.foodchem.2005.03.028

[4] Ghafar, M.F.A., Prasad, K.N., Weng, K.K. and Ismail, A. (2010) Flavonoid, Hesperidine, Total Phenolic Contents and Antioxidant Activities from Citrus Species. African Journal of Biotechnology, 9, 326-330. 